\title{
INDEFINITE STURM-LIOUVILLE OPERATORS WITH PERIODIC COEFFICIENTS
}

\author{
FRIEDRICH PHILIPP
}

\begin{abstract}
We investigate the spectral properties of the maximal operator $A$ associated with a differential expression $\frac{1}{w}\left(-\frac{d}{d x}\left(p \frac{d}{d x}\right)+q\right)$, where the coefficients $w, p$ and $q$ are real-valued and $w$ changes sign. It turns out that the non-real spectrum of $A$ is bounded, symmetric with respect to the real axis and consists of a finite number of analytic curves. The real spectrum is band-shaped and neither bounded from above nor from below. We characterize the finite spectral singularities of $A$ and prove that there is only a finite number of them. Finally, we provide a condition on the coefficients $w$ and $p$ which ensures that $\infty$ is not a spectral singularity of $A$.
\end{abstract}

Mathematics subject classification (2010): 34B09, 34B24, 34L10, 47B50, 47E05.

Keywords and phrases: Sturm-Liouville operator, periodic coefficients, indefinite weight.

\section{REFERENCES}

[1] T. YA. AzIZOV AND I. S. IoKHVIDov, Linear operators in spaces with an indefinite metric, John Wiley \& Sons, Ltd., 1989.

[2] J. BEHRNDT, On the spectral theory of singular indefinite Sturm-Liouville operators, J. Math. Anal. Appl. 334 (2007), 1439-1449.

[3] J. BEhRNDT AND F. PhilipP, Spectral analysis of singular ordinary differential operators with indefinite weights, J. Differential Equations 248 (2010), 2015-2037.

[4] J. Behrndt And C. TRunk, On the negative squares of indefinite Sturm-Liouville operators, J. Differential Equations 238 (2007), 491-519.

[5] C. Bennewitz AND W. N. EveritT, On second-order left-definite boundary value problems, Lect. Notes Math. 1032, Springer (1983), 31-67.

[6] P. BINDING AND P. BROWNE, Left definite Sturm-Liouville problems with eigenparameter dependent boundary conditions, Differ. Integral Equ. (2) 12 (1999), 167-182.

[7] P. Binding, P. BROWNE AND B. WATSON, Inverse spectral problems for left-definite Sturm-Liouville equations with indefinite weight, J. Math. Anal. Appl. 271 (2002), 383-408.

[8] P. BINDING AND M. MÖLLER, Negativity indices for definite and indefinite Sturm-Liouville problems, Math. Nachr. 283 (2010), 180-192.

[9] P. Binding AND H. Volkmer, Eigencurves for two-parameter Sturm-Liouville equations, SIAM Rev. 38 (1996), 27-48.

[10] J. BognaR, Indefinite inner product spaces, Springer, Berlin, Heidelberg, New York 1974.

[11] J. B. CONWAY, Functions of one complex variable, Springer, New York 1978.

[12] B. ĆURGUS, On the regularity of the critical point infinity of definitizable operators, Integral Equations Operator Theory 8 (1985), 462-488.

[13] B. ĆURGUS AND H. LANGER, A Krein space approach to symmetric ordinary differential operators with an indefinite weight function, J. Differential Equations 79 (1989), 31-61.

[14] K. DAHO AND H. LANGER, Sturm-Liouville operators with an indefinite weight function: The periodic case, Rad. Mat. 2 (1986), 165-188.

[15] R. DenK, M. MöLler And C. TRetTer, The spectrum of the multiplication operator associated with a family of operators in a Banach space, Oper. Theory Adv. Appl. 162 (2005), 103-116.

[16] A. Dijksma AND H. S. V. DE SNOo, Symmetric and self-adjoint relations in Krein spaces I, Oper. Theory Adv. Appl. 24 (1987), 145-166. 
[17] M. S. P. EAstham, The spectral theory of periodic differential equations, Scottish Academic Press, London 1973.

[18] F. GESZTESY AND V. TKACHENKO, A criterion for Hill operators to be spectral operators of scalar type, J. Anal. Math. 107 (2009), 287-353.

[19] S. Hassi, M. M. Malamud And H. S. V. DE Snoo, On Krein's extension theory of nonnegative operators, Math. Nachr. 274/275 (2004), 40-73.

[20] P. JonAs, On locally definite operators in Krein spaces, In: Spectral Theory and its Applications, Ion Colojoară Anniversary Volume, Theta 2003, 95-127.

[21] I. M. Karabash And A. S. Kostenko, Indefinite Sturm-Liouville operators with the singular critical point zero, Proc. Roy. Soc. Edinburgh Sect. A 138 (2008), 801-820.

[22] I. M. Karabash, A. S. Kostenko and M. M. Malamud, The similarity problem for J-nonnegative Sturm-Liouville operators, J. Differential Equations 246 (2009), 964-997.

[23] I. M. KARABASH AND M. M. Malamud, Indefinite Sturm-Liouville operators $(\operatorname{sgn} x)\left(-\frac{d^{2}}{d x^{2}}+q(x)\right)$ with finite-zone potentials, Oper. Matrices 1 (2007), 301-368.

[24] I. M. Karabash And C. TRUnK, Spectral properties of singular Sturm-Liouville operators, Proc. Roy. Soc. Edinburgh Sect. A 139 (2009), 483-503.

[25] T. Kato, Perturbation theory for linear operators, Second Edition, Springer, Berlin, Heidelberg, New York 1976.

[26] Q. KOnG, H. Wu AND A. ZETtL, Left-definite Sturm-Liouville problems, J. Differential Equations 177 (2001), 1-26.

[27] Q. Kong, H. Wu And A. Zettl, Singular left-definite Sturm-Liouville problems, J. Differential Equations 206 (2004), 1-29.

[28] A. Kostenko, The similarity problem for indefinite Sturm-Liouville operators with periodic coefficients, Oper. Matrices 5, 4 (2011), 707-722.

[29] H. LAnger, Spectral functions of definitizable operators in Krein spaces, Lect. Notes Math. 948, Springer (1982), 1-46.

[30] H. LANGer, A. MARKUS AND V. MATSAEV, Locally definite operators in indefinite inner product spaces, Math. Ann. 308 (1997), 405-424.

[31] H. Langer And C. Tretter, A Krein space approach to PT-symmetry, Czech. J. of Phys. 54 (2004), 1113-1120.

[32] M. Marletta And A. Zettl, Floquet theory for left-definite Sturm-Liouville problems, J. Math. Anal. Appl. 305 (2005), 477-482.

[33] H. Radjavi and P. Rosenthal, Invariant Subspaces, Dover Publications, Inc., Mineola, New York 2003.

[34] O. A. VelieV, Spectrum and spectral singularities of differential operators with complex-valued periodic coefficients, Differ. Equations 19 (1983), 983-989.

[35] J. Weidmann, Spectral theory of ordinary differential operators, Lect. Notes Math. 1258, Springer (1987).

[36] J. Weidmann, Lineare Operatoren in Hilberträumen. Teil II: Anwendungen, Teubner, Wiesbaden 2003 (German).

[37] V. A. YAKUBOVICH AND V. M. StARZHins KiI, Linear differential equations with periodic coefficients. Vol. 2, John Wiley\& Sons, New York - Toronto 1975.

[38] A. ZETTL, Sturm-Liouville theory, AMS, Providence, RI 2005. 